\title{
MITOLOGİA Y ORGANIZACIÓN SOCIAL ENTRE LOS "LACANDONES" (HACH WINIK) DE LA SELVA CHIAPANEGA
}

\author{
Didier Boremanse \\ Universidad del \\ Valle de Guatemala
}

\section{Introducción}

Los mayas "lacandones" de la selva de Chiapas se designan a sí mismos como Hach Winik, expresión que significa "los Verdaderos Hombres" en su idioma yucateco. Ellos no descienden de los lacandones que ocuparon el mismo territorio durante la época colonial, y que fueron reducidos y deportados por los españoles (de Vos, 1980, cap. V, VII, IX). Estos habitantes originales de la selva lacandona no hablaban yucateco sino "una variante del cholti" (ibid.: 175), y su cultura era distinta a la de los Hach Winik actuales (Boremanse 1971:28-58).

La palabra "lacandón" o "lacantun" deriva aparentemente del maya acantun que tenía varios significados, ${ }^{1}$ entre ellos "piedra erecta" y "gran peñón". Según las fuentes históricas, los conquistadores y

1 Scholes y Roys $(1948: 40)$ y luego de Vos (1980:57) dicen que lacam tun significa "gran peñón". Roys (1965:xiv) traduce acantun por "fuste de piedra" (stoneshaft), y relaciona la palabra con un contexto ritual, refiriéndose a una descripción de Diego de Landa: "Venida la madera, hacían una casilla de paja, cercada, donde la metían y una tinaja para echar a los ído'os y allí tenerlos tapados según los fuesen haciendo; metían incienso para quemarle a cuatro demonios llamados Acantunes, que ponian a las cuatro partes del mundo" (Landa 1978:101). Bruce (1975:4) da una interpretación similar y sugiere que el significado "ídolos de piedra" se extendió a "los que adoran piedras". Debido a la polisemia del término acantun; tanto la traducción de Scholes y Roys, y de Vos (1980:331) citando a Remesal, como la de Bruce y Roys citando a Landa nos parecen válidas. 
sus acompañantes indígenas llamaron "el acantún" a una isla del lago Miramar donde hallaron, en el siglo xvi, un poblado de indios chol o cholti. Luego 'el acantun' se transformó en 'lacantún', y finalmente en 'lacandón', y este término se aplicó a toda el área y a sus habitantes (Scholes y Roys 1948:41). Así "los del acantun" se volvieron "los lacantunes", y después "los lacandones".

Después de ser conquistada, la selva lacandona quedó casi despoblada. En los siglos xviI-xvirr, a medida que el número de habitantes iba reduciéndose, varios grupos de emigrantes originarios de Yucatán, Campeche, Tabasco, y también del Petén (Guatemala) se establecieron en la región abandonada por sus antiguos moradores, mezclándose con los que aún no habían sido reducidos (de Vos 1980: 232-236). Los invasores hablaban distintos dialectos del yucateco. Entre ellos estaban los antepasados de los Hach Winik actuales quienes, paulatinamente, pasaron del este al oeste del río Usumacinta. A ellos también se les aplicó el término lacandón, confundiéndolo con los indios rebeldes que habían ocupado esta tierra desde los tiempos precolombinos, y habían sido aniquilados por los conquistadores (Hellmuth 1972:182, 207; de Vos 1980). Desde luego la palabra 'lacandón' tiene una connotación geográfica, sin embargo queda desprovista de toda significación de tipo étnico.

El nombre Hach Winik tampoco designa a una cultura maya homogénea. Hoy se hace la distinción entre los 'lacandones del norte' y los 'lacandones del sur' (Baer y Merrifield 1972:9). Los primeros viven actualmente cerca de las lagunas de Ts'ibatnah, K'ak, Mensabäk, y Naha, vale decir en el noroeste de la selva lacandona. Sus antepasados ya moraban al sur de Palenque a fines del siglo xvm (AGCA, A1, 12, 118, 2483). Los segundos están agrupados ahora en Lacanha Chan Sayab, cerca de Bonampak. Sus ancestros emigraron desde la cuenca del río de la Pasión hacia Chiapas en el siglo pasado, y permanecieron en el sureste de la selva. Estos dos grupos de Hach Winik son lingüística, cultural y socialmente distintos, y no tuvieron ningún contacto uno con otro hasta tiempos recientes. Los tremendos cambios ambientales que están ocurriendo en la selva chiapaneca han modificado radicalmente esta situación.

Entre 1974 y 1981 diez familias del noroeste se trasladaron a Lacanha Chan Sayab y, por primera vez, miembros jóvenes de estas dos sociedades se han casado entre sí. Este fenómeno constituye un cambio socio-cultural importante, puesto que el patrón de residencia post-marital no es idéntico en ambas sociedades. No cabe duda que, al contraer matrimonio entre sí, los Hach Winik del 
norte y los del sur están contribuyendo a la creación de un nuevo sistema social, lo que, a la vez, representa una especie de experimento sociológico. Ello podría ser el tema de un estudio futuro. Por lo pronto nos limitaremos a considerar la institución matrimonial de los Hach Winik en su forma tradicional y como se ve reflejada en la mitología.

Los mitos $^{2}$ estudiados aquí describen los matrimonios imposibles entre seres humanos y animales (jaguar, perro, zopilote, mono, pecarí), y refieren a ideologías distintas de las dos sociedades lacandonas así como a diferentes principios de organización social. En ambas sociedades la función manifiesta del matrimonio es la de proporcionar comida. Un hombre dirá, por ejemplo, que quiere conseguir una esposa para que le haga las tortillas. Pero a un nivel más profundo de la estructura social la institución matrimonial desempeña una función diferente en cada sociedad en relación con el sistema de residencia respectivo.

Los Hach Winik tuvieron que renunciar a su patrón de asentamientos disperso a causa de la invasión de la selva por otros grupos de campesinos mexicanos. Sin embargo, dentro de las tres comunidades lacandonas actuales el caserío o grupo de casas sigue siendo la unidad de residencia básica. Entre los 'lacandones meridionales' el yerno tiene que establecerse en el caserío de sus suegros, y trabajar para ellos "hasta que mueran", por lo menos en teoría. Pero es muy poca la discrepancia entre la regla y la conducta en cuanto al patrón de residencia, dado que en 1979 la residencia de la mayoría $(90 \%)$ de los hombres casados en Lacanha Chan Sayab era del tipo uxorilocal ${ }^{3}$ (Boremanse 1981a:7). Es relativamente fácil ob-

2 Todo el material etnográfico fue recogido por el autor quien convivió con los Hach Winick durante 21 meses entre 1970 y 1981. Los mitos fueron grabados, transcritos y traducidos en la selva con la colaboración de Chan K'in y K'ayum Ma'ax, Nuxi, José Valenzuelo en el noroeste, y gracias a la ayuda de $\mathrm{K}$ 'in Yuk en Lacanha Chan Sayab. A todos ellos mi más sincero agradecimiento. También se agradece muchísimo a Doña Gertrudis de Blom por su generosa y constante ayuda durante más de diez años, así como a Ken Nelson, y al Lic. A. Robles R., Director de Asuntos Indígenas entre 1970 y 1976 . El Sr. R. Boremanse financió la investigación y Verónica Leija V. ayudó a la corrección del presente artículo.

${ }^{3} \mathrm{La}$ unidad familiar entre los Hach Winik es la familia nuclear, y generalmente, cada familia ocupa una choza propia. Sin embargo, un yerno en servicio se establece en la casa de sus suegros durante los primeros meses de su matrimonio, y luego construye su propia casa. También ocurre que un hijo casado se quede en la casa de sus padres, especialmente si se trata de un hijo joven. Cuando dos familias viven bajo el mismo techo cada 
tener una esposa en el sureste porque precisamente los padres no pierden a su hija; al contrario adquieren un yerno del cual se esperan prestaciones económicas. En tal caso, el hombre que desea casarse sólo pide la mujer a sus padres, y si ellos lo quieren como yerno se la dan sin ninguna ceremonia. La madre sólo pregunta a su hija si ella está dispuesta a dar de comer al hombre que la quiere como esposa, si la respuesta es positiva el arreglo queda concluido.

En cambio, entre los 'lacandones septentrionales' el hecho de pedir una esposa implica un largo y penoso proceso. ${ }^{4} \mathrm{El}$ pretendiente tiene que solicitar a la mujer dos veces. Es raro cuando las dos peticiones se llevan a cabo el mismo día. Normalmente pueden transcurrir semanas, meses, y a veces años entre las dos etapas de este proceso. La manera como se solicita la esposa es muy formal. El pretendiente llega como un simple visitante a la casa del padre cie la mujer cuya mano quiere pedir, y hace su demanda en la noche. La regla es que uno pide una esposa sólo después de la puesta del sol y antes de su salida, y durante estas horas tanto el pretendiente como su suegro potencial no deben dejar de fumar cigarros de hoja, los cuales son proporcionados por el visitante. El diálogo entre los dos se vuelve una verdadera contienda verbal, ya que el padre de la mujer siempre empieza por rechazar la demanda, y el pretendiente lo tiene que convencer poco a poco. La conversación es estereotipada en el sentido de que cada interlocutor sabe más o menos lo que tiene que decir y lo que el otro va a contestar. En efecto ambos siguen un patrón cultural. Por ejemplo, el padre dirá: "mi hija es perezosa, no te hará la comida", y el pretendiente contestará: "yo también soy perezoso, no trabajo, no tenga milpa, dámela". - "No te la daré es muy sucia". "Yo también soy sucio, dámela", etc. El carácter humorístico del diálogo no significa que no haya una tensión

una ocupa una extremidad de la choza y tiene su propio fuego. El término 'uxorilocalidad' significa que la residencia de una familia es la misma que la de los padres de la mujer, vale decir que las dos familias ocupan chozas vecinas dentro de un mismo caserío. En cambio, la residencia de una familia es 'virilocal' cuando ésta vive en el caserío en que viven los padres del marido. En el pasado, cuando el patrón de asentamiento era desparramado, varias familias vivían en forma aislada (sin ningún vecino), su residencia era 'neolocal'. Hoy, en las comunidades lacandonas actuales (donde la concentración de gente es mayor) se dan casos de residencia 'ambilocal', cuando los padres respectivos del hombre y de la mujer habitan en el mismo caserío.

4 Este proceso ha sido descrito destalladamente en un trabajo anterior (Boremanse 1978:232-251). 
psicológica y una oposición latente entre los dos hombres. Frecuentemente el padre de la mujer habla en un tono enojado como para tratar de desanimar al pretendiente pero éste no debe dejarlo en paz, ni siquiera para dormir un poco. Tiene que seguir pidiendo y fumando sus puros. Esta petición ritual puede durar varias noches, y hasta puede incluir varias visitas de parte del pretendiente. Para obtener a la mujer él tiene verdaderamente que rogar a sus padres, y después de conseguirla se queda en la casa y debe trabajar para ellos durante un cierto tiempo.

Después de cumplir con su servicio de yerno vuelve a pedir a su esposa, pero antes de iniciar la petición nocturna tiene que cortar leña y hacer un fuego para su suegra. Este fuego simboliza la donación de la mujer, dado que después de aceptarlo los suegros ya no pueden ejercer ningún control sobre su yerno. Este tiene la total libertad de dejarlos, y de regresar con su esposa a la localidad donde vivía anteriormente (generalmente en el caserío de sus padres), o a cualquier otro lugar que le convenga. Opinamos que la humillación ritual del pretendiente (él tiene que deprecar a la mujer para mostrar que de veras la quiere) así como la ambivalencia de la contienda verbal reflejan simbólicamente la oposición entre donador y tomador de esposa, el hecho de que los suegros no pueden esperar una prestación importante de parte de su yerno, y también la ausencia de una regia de residencia bien definida. Este hecho se ve confirmado por los estudios empíricos realizados en 1979. El 34.92 por ciento de las familias lacandonas en el noroeste se hallaban en residencia uxorilocal mientras que el 31.74 por ciento vivía virilocalmente. La residencia de las demás familias era de otro tipo (ambilocal, neolocal, etc.) (Boremanse 1981a:6). Veremos más adelante que la ambigüiedad de este patrón de residencia se expresa en la estructura del siguiente conjunto mítico.

\section{RESÚMENES DE LOS MITOS DE LOS HACH WINIK DEL NORTE}

Historia del matrimonio de un hombre con un zopilote

Hace mucho tiempo las mujeres eran escasas, y la mayoría de los hombres tenía que preparar su propia comida. Por lo tanto, un antepasado tuvo que casarse con un zopilote. ${ }^{5}$ Un día sorprendió a

\section{${ }^{5}$ Zopilote real, Maya: Chom, Latín: Sarcoramphus papa.}


dos zopilotes hembras que estaban bañándose en un río. Se habían quitado las plumas y tenían apariencia de mujeres; se limpiaban la cabeza con limón. El hombre logró capturar a una de ellas y la otra se escapó. "Suéltame! Suéltame!", dijo la cautiva. "No tengo mujer", contestó el hombre. "¿Crees que serás un buen esposo?”, preguntó ella. Le respondió que sí, y se la llevó. En su casa le dio la ropa de su madre que había muerto. Después de habérsela puesto la mujer-zopilote parecía completamente humana, y el antepasado la tomó como esposa. Un día ella lo invitó a que conociera la casa de sus padres y de toda su parentela en el cielo ${ }^{6}$ de los zopilotes. En aquel tiempo existía un camino entre este lugar y la selva. Allí el ancestro vio a mucha gente, y también había muchas milpas. Todos los zopilotes parecían humanos, no llevaban plumas sino una túnica. El hombre platicó con el señor de los zopilotes. Era calvo y tenía los dientes amarillos. El señor de los zopilotes dijo al antepasado que su alma no iría con $\mathrm{Kisin}^{8}$ después de su muerte, sino que se vendría al cielo de los zopilotes. Pero no se sabe si efectivamente así sucedió porque después de haber regresado a su casa el hombre se portó muy mal con su mujer-zopilote. Empezó a menosprcciarla porque comía carne podrida. Ella decía que los gusanos de la carroña eran chiles, le gustaban muchísimo. Pero su marido estaba disgustado. Cuando había cazado algo la mujer-zopilote esperaba a que la carne estuviese en estado de descomposición antes de cocinarla. Finalmente el antepasado la abandonó y se fue a vivir en su milpa. Durante su ausencia un $X o k^{9}$ vino y tuvo una relación con su esposa, la cual se quedó embarazada. Cuando volvió el hombre a su casa encontró a su esposa muy mal, a punto de morir. Ella le confesó su aventura, y después le dijo: "Tienes que abrir mi vientre sacar a los hijos de Xok, y matarlos". El ancestro encontró diez pequeños cocodrilos en el vientre de su esposa, y los mató. Antes de morir le dijo ella: "Abre mi meñique, encontrarás pepitas de calabaza, siémbralas en tu milpa, son nuestras hijas". Le explicó cómo tenía que cuidar de las calabazas, le enseñó la técnica de cultivo, y le dijo que tenía que ponerlas en la cocina después de haberlas

6 Los Hach Winik creen que el cielo que vemos es el cielo de los zopilotes, que está colgado bajo el cielo de Hachäkyum, el Creador.

' Muchas especies animales tienen un 'señor' (yum). El término yum también significa 'padre', 'tío paterno'.

8 Kisin, dios del Mal y de la Muerte, quien quema las almas de los muertos por sus pecados en el fuego del Inframundo.

${ }^{9}$ Xok, ser acuático mitológico, procurador de los peces. 
cosechado. Luego murió y su marido hizo exactamente lo que ella había indicado. El se quedó solo, sin esposa. Tres calabazas crecieron, pero destruyó a una por accidente, y puso a las otras dos en la cocina. Un día, al regresar a su casa, encontró atoles y tortillas calientes; y lo mismo sucedió los días siguientes. Cuando regresaba a casa encontraba el maíz molido y la comida lista. Un día regresó más temprano y sorprendió a dos mujeres desnudas que estaban moliendo maíz en la cocina. Eran sus hijas, las que habían crecido en las calabazas. Solían salir de la calabaza durante el día para preparar la comida de su padre y volvían a meterse poco antes de su llegada. El ancestro tuvo que darles la ropa de su esposa-zopilote. Se vistieron y le dijeron que había tratado muy mal a su madre. Entonces él lloró. Sus hijas estuvieron con él y le hicieron de comer. Luego vino un vecino a pedirle la mano de ellas, dijo que le iba a dar una de sus hermanas menores a cambio. Quería una mujer para él y la otra para su hermano menor. Los dos hombres se pusieron de acuerdo e hicieron el intercambio. De este modo el antepasado consiguió una esposa, pero murió un año después. Sus hijas tuvieron hijos, nietos, y bisnietos. Por esta razón está prohibido matar a los zopilotes. Los dioses habían permitido la metamorfosis de un zopilote y su matrimonio con un hombre porque las mujeres eran escasas. Empero, debido al hecho de que el antepasado se portó mal con su esposa-zopilote, los dioses ya no permitieron que tales acontecimientos volviesen a ocurrir.

\section{Historia del matrimonio de un hombre con su perra}

Un antepasado tenía una perra. Ella lo acompañaba siempre cuando caminaba en la selva. Pero un día que iba a sacar la resina de los árboles de copal lo abandonó su perra a mitad del camino. Después de haber recogido la resina de copal el hombre regresó a casa donde lo esperaba la perra. Ésta empezó a brincar y a gemir como si quisiese decirle algo. Por fin el ancestro vio las tortillas y el atole caliente preparados para él, y se sentó a comer. Lo mismo sucedió los otros días. La perra siempre lo dejaba cuando salía, y pasaba la mayor parte de su tiempo en casa. Cuando volvía el hombre la comida estaba lista. Él quiso saber lo que pasaba y, un día, regresó más temprano para sorprender a su perra. Cuando llegó vio a una mujer desnuda que estaba moliendo maíz. Los pelos de la perra estaban en el suelo. Ella se había transformado en una 
mujer. El hombre la atrapó. "¿Serás un buen marido?", le preguntó la mujer-perra. Él contestó que sí, y le dio ropa de mujer. Una vez vestida la perra parecía completamente humana, y el antepasado se casó con ella. Tuvieron hijas, pero la mujer-perra comía los excrementos de las niñas, y ella misma defecaba en las ollas. Su marido le pegó mucho, pero ella no podía cambiar porque así hacen los perros. Por fin el ancestro se hartó de encontrar excrementos en la comida, y le pegó tanto que la mató. Se quedó con sus dos hijas que le hacían su comida. Ellas crecieron y otro hombre vino a pedir su mano. Los dos hombres hicieron un intercambio. El viudo de la perra cedió sus hijas al otro y recibió una esposa a cambio, pero murió poco después. Hoy los perros ya no se vuelven humanos. No obstante es muy malo matar a un perro. Quien mata a un perro se quemará en el fuego de Kisin como si hubiese matado a un ser humano.

\section{Historia del hombre que tuvo que casarse con una mona}

Un cazador mató a muchísimos monos-arañas ${ }^{10}$ de una manera muy cruel. Les disparó flechas en los brazos y las piernas de tal modo que los pobres animales sufrieron mucho antes de morir. Ni siquiera comía la carne, sino que tiraba los cuerpos y los dejaba podrir en la selva. Entonces el señor de los monos convocó una junta, y todos los monos decidieron raptar al culpable. Mientras el antepasado caminaba en la selva los monos lo rodearon, lo atraparon, y se lo llevaron arriba de los árboles. Allí extrañó a su esposa, a su padre, pero los monos no lo dejaron volver a su casa. Además el señor de los monos lo obliǵ́ a procrear monos para reemplazar todos los que había matado. Se tuvo que casar con una mona, entre todas pudo escoger la que más le gustaba. Anduvo en la cima de los árboles, recolectando frutos salvajes, y cada vez que tenía una espina en el pie o en la mano los monos se la sacaban con sus dientes y le mordían. “iEso me duele!”, gritaba el hombre. Entonces el señor de los monos le recordaba el dolor que él había causado a todas sus víctimas. El antepasado estuvo casi dos años con los monos, y después pudo escaparse y volver a su casa. Contó su historia a sus parientes, y ellos le dijeron que los monos lo habían castigado porque él los había cazado de una manera muy cruel. El hombre es-

10 Mono-araña, Maya: Ma’ax, Latín: Ateles geoffroyi. 
tuvo un mes con su familia, y luego murió. No se sabe si su alma se fue con los dioses o con el señor de los monos.

\section{Historia del hombre que tuvo que casarse con un pecarí}

Algo semejante sucedió a un antepasado que había cazado pecarís con flechas arpadas. ${ }^{11}$ Había matado a un pecarí y había herido a otro y lo estaba persiguiendo cuando llegó a una milpa en la cual escuchó una voz orando. Era un pecarí que estaba rezando para tratar de curar a la hembra perseguida por el cazador. Éste era valiente y se acercó con sus flechas. El señor de los pecarís le preguntó quién había matado y herido a sus hijas con flechas barbadas. "Yo", dijo el hombre. "No puedes hacer eso", dijo el señor de los pecarís, "ahora tienes que curar a mi hija". Afortunadamente el cazador conocía el encantamiento terapéutico ${ }^{12}$ contra este tipo de heridas. Recitó el conjuro durante toda la noche y logró curar al animal. Luego el señor de los pecarís le ofreció a una de sus hijas, y el ancestro se casó con ella. Estuvo casi dos años entre los pecarís quienes lo trataron muy bien. Cuando uno de ellos [era] alcanzado por una flecha el hombre lo curaba con sus conocimientos mágicos. Estaba feliz con su esposa-pecarí. Pero un día otro cazador la mató. El estaba desesperado y gritó: " $i$ Acabas de matar a mi esposa!" “ ¿Cómo puede ser tu esposa?", contestó el otro, "i es carne de caza, la vamos a comer!". El marido del pecarí estaba indignado. Los dos hombres cargaron al animal muerto hasta el caserío. Alli los otros asaron al pecarí y lo comieron. El viudo no comió. Estaba muy triste. Los otros hombres le dijeron que podía volver a casarse con una mujer. "Hay mujeres aquí", decían. Pero él no quiso. Extrañaba demasiado a su esposa-pecarí. Tres días después murió de tristeza, y sus parientes lo enterraron.

\section{Historia del jaguar que raptó una niña y se casó con ella}

Un jaguar ${ }^{13}$ raptó a la hija de un antepasado cuando él estaba ausente. Luego, durante la noche, el jaguar volvió a la casa del

11 Las flechas armadas con púas sólo pueden usarse para cazar al mono, dado que él saca las flechas de su cuerpo con sus manos. Es malo cazar cualquier otro animal con flechas barbadas.

12 Encantamiento terapéutico, (Cf. Boremanse 1979).

13 Jaguar, Maya: Balum, Latín: Felis onca. 
hombre, y robó tortillas, atole y fuego para su esposa. El antepasado no supo nada más de su hija. Un año después caminaba en la selva y oyó la voz de una niña llorando. Se acercó a ella y encontró a su hija en una cueva abajo de una roca. La niña suplicó a su padre que no matara ni hicera daño a su yerno. En aquel tiempo jaguares y hombres no eran enemigos, y el ancestro dijo que no haría ningún daño al jaguar. Éste había ido a cazar. El hombre preguntó a su hija si comía carne cruda. "Nc, padre, ¡ tenemos fuego!", le contestó, y le ofreció un poco de carne asada. Había una gran cantidad de carne en la casa del jaguar: mono, pecarí, faisán, etc, $\mathrm{Al}$ atardecer llegó el jaguar cargando un pecarí. Saludó a su suegro y le dijo: "Me casé con tu hija porque me gustaba mucho, no me hagas daño". Luego ofreció dos pecarís a su suegro. Como éste no los podía cargar, el jaguar lo ayudó y lo acompañó hasta su caserío. Allí vio a sus cuñados quienes lo trataron muy bien, le dieron atole y tortillas, y el jaguar se llevó esta comida a su casa. Más tarde volvió y preguntó a su suegro si podía venir a vivir cerca del caserío. El hombre le dijo que sí. Entonces el jaguar se estableció cerca de los hombres. Los invitaba a comer en su casa, y les daba mucha carne asada. Todos estaban muy contentos. Pero un vecino, por envidia, mató al jaguar. Le disparó una flecha cuando andaba en la selva. Después de matarlo fue a su casa, y masacró a sus niños quienes llevaban una túnica pintada como piel de jaguar. "No son humanos, ; son jaguares!", dijo el asesino. El suegro del jaguar lamentó este crimen y condenó la conducta del asesino. La esposa del jaguar murió de tristeza. El asesino justificó su acto diciendo que los jaguares no deben casarse con humanos. Desde entonces los jaguares están enojados con los hombres; ya no les regalan carne, sino que los muerden. Antes los jaguares no devoraban a los hombres.

\section{Análisis}

Los protagonistas animales en estos mitos, excepto el jaguar, manifiestan ciertos rasgos humanos. ${ }^{14}$ Los zopilotes tienen apariencia humana cuando se deshacen de sus plumas, ${ }^{15}$ llevan una túnica y cul-

14 "No hay que olvidar, en efecto, que en los tiempos míticos los hombres se confundían con los animales" (Lévi-Strauss 1968:116).

15 Existe un mito muy parecido entre los indios Warao del delta del Orinoco (Wilbert 1970:343-345). El relato del matrimonio de un hombre con su perra también se encuentra entre los Arawak de Guyana (Drummond 1977:847-848). 
tivan maíz. La perra se transforma en mujer. Los monos tienen sentido de la justicia, y los pecarís rezan para curar a los enfermos. Al mismo tiempo, estos animales "humanizados" conservan sus características más profundas. La mujer-zopilote come carne podrida, la mujer-perra es sucia, los monos y los pecarís conservan hasta su forma animal. El jaguar ocupa una posición especial porque, a diferencia de los otros animales, él no está en posición de donador, sino de tomador de esposa ante los hombres. ${ }^{16}$ En realidad los Hach Winik no consideran al jaguar como a cualquier animal, y están conscientes del hecho, subrayado por Lévi-Strauss, de que "el jaguar se come al hombre, pero el hombre no come jaguar" (1968:87). Además el jaguar es rival ${ }^{17}$ del hombre porque ambos cazan a los mismos animales. En este sentido es interesante observar que pueblos selváticos, tanto en América del sur como en Mesoamérica, relatan en sus mitos el matrimonio del jaguar con una mujer, y también el hecho de que la alianza y la amistad que entonces unían al jaguar con los humanos fueron $\operatorname{rotas}^{18}$ por la culpa de estos últimos. En efecto, los mitos lacandones anteriormente mencionados enfatizan la mala conducta del hombre como causa del fracaso de los matrimonios con animales, y emiten juicios morales. Los dioses habían permitido tales matrimonios, y ahora ya no los permiten a causa del comportamiento humano. Una de las causas de este fracaso es entonces de orden moral. Otra es de orden categorial. Se trata de una imposibilidad lógica expresada por la oposición entre las categorías de cultura y naturaleza. ${ }^{19}$

A pesar de haberse transformado en mujer, la zopilote sigue comiendo carne podrida y la perra sigue defecando en cualquier lado.

16 Dice Lévi-Strauss: "el jaguar está en posición de tomador de mujer ante un grupo humano. Pero es un cuñado benévolo, que da a los hombres el fuego de cocina - o la carne asada - a cambio de la esposa que de de ellos recibe" (1968:94). En el mito lacandón es más bien el jaguar quien roba fuego en la casa de sus suegros; pero luego les ofrece carne asada.

17 "Para el hombre el jaguar es un temible competidor por su fuerza, su agilidad, lo agudo de su vista y de su olfato" (Reichel-Dolmatoff 1949-50: 266-267).

18 "Pero el jaguar, furioso... quedará lleno de odio hacia todos los seres y en especial hacia el género humano" (Lévi-Strauss 1968:72).

19 Drummond sugiere que al substituir la oposición Cultura: Naturaleza con la oposición Nosotros: Ellos la estructura de tales mitos puede revelar el modelo de identidad de una sociedad particular en su relación con otras (1977:855-857). 
La mona arranca las espinas del cuerpo de su marido con sus dientes; y la esposa-pecarí muere, víctima de un cazador.

Otros valores culturales se hallan expresados en estos mitos. La función manifiesta de la institución matrimonial, entre los Hach Winik, es de producir y distribuir los alimentos por medio de la división del trabajo. Los esposos cooperan económicamente, y siempre comen juntos. Cuando un hombre quema copal para su esposa se refiere a ella, en sus oraciones, usando la expresión in wet hanan, "con quien como". En los mitos la comida y la división del trabajo entre los esposos están frecuentemente mencionados. Pero otros principios de organización social aparecen también en éstos en una forma más encubierta.

Casi todos los casamientos entre humanos y animales son resultado de raptos. En el mundo real un hombre que quiere adquirir una esposa tiene que pedirla a sus padres, y tiene que pedirla según un proceso bien establecido. $\mathrm{O}$ sea, los mitos nos dan una imagen inver$\operatorname{tida}^{20}$ de la realidad. En la introducción del presente ensayo se ha formulado la hipótesis de que la petición ritual que un hombre lleva a cabo para obtener una esposa refleja una situación ambigua. La residencia marital no está determinada por una regla bien definida. Los padres de la mujer no tienen la certeza de que su futuro yerno se quedará con ellos. En este sentido la contienda verbal que opone al tomador de esposa con el donador de esposa simboliza una oposición entre dos principios de organización social, la residencia virilocal, y la residencia uxorilocal. En efecto, la misma oposición se da en los mitos. En los casos en que la mujer es raptada (zopilote, perra, jaguar) la residencia es virilocal, mientras que cuando el hombre ha sido raptado (por los monos o por los pecarís) la residencia es uxorilocal.

Estas variables se aprecian mejor en la siguiente serie de oposiciones:

Zopilote/perra

apariencia humana

escasez de esposas

esposa raptada mono/pecarí

apariencia animal

abundancia de esposas

marido raptado

20 "La relación del mito con lo dado es cierta, pero no en la forma de una re-presentación. Es de naturaleza dialéctica, y las instituciones descritas en los mitos pueden ser opuestas a las instituciones reales" (Lévi-Strauss 1972:59-60). 
residencia virilocal ninguna prestación mala comida mal marido residencia uxorilocal prestación del marido buena comida buen marido

Estas oposiciones corroboran la idea de Lévi-Strauss según la cual "el significado de un conjunto de mitos no reside en el sentido aparente de los relatos, sino en las relaciones que existen entre ellos" (Leach 1970:28). Por otro lado, es cierto que un mito "sólo puede entenderse en su contexto cultural" (ibid:27). No nos parece oportuno plantear el problema de saber si el mito debe considerarse como una descripción de la realidad etnográfica o como la expresión de estructuras latentes, puesto que para nosotros estas dos concepciones no se contradicen, sino más bien se complementan. No cabe duda de que los cinco mitos estudiados aquí forman un todo estructurado, y que, a la vez, reflejan ${ }^{21}$ importantes rasgos de la organización social lacandona.

La escasez de mujeres (que obligó a un antepasado a casarse con un zopilote y a otro con su perra) ha sido un problema grave para los Hach Winik en el siglo pasado. Fue posiblemente causado por una fuerte disminución de la población debida a epidemias, y por la práctica del la poliginia. El intercambio matrimonial directo y el matrimonio con niñas son prácticas a las cuales han recurrido y siguen recurriendo los hombres para luchar contra esta escasez de esposas. Ambas prácticas son mencionadas en los mitos. El jaguar se casa con una niña. Los ex-maridos respectivos de la mujer-zopilote y de la mujer-perra dan sus hijas a cambio de una esposa humana.

Los esposos comen juntos y cooperan en la producción de los alimentis. La mujer prepara las tortillas, el atole; el hombre cultiva el maíz y caza. Esta forma de división del trabajo se expresa en los mitos. También vemos que la residencia uxorilocal está asociada con prestaciones, mientras la residencia de tipo virilocal no implica ninguna prestación. La etnografía muestra que un yerno en servicio vive bajo el mismo techo que sus suegros, y un hombre establecido cerca de su padre ya no trabaja para su suegro. En cambio la asociación de la residencia virilocal con una escasez de esposas y la asociación de la residencia uxorilocal con una abundancia de

21 Para Boas la mitología de un pueblo describe su vida, su organización social, sus creencias y prácticas religiosas (1916:32). 
esposas nos parece que refleja una ideología más bien que una situación concreta, aunque existe la probabilidad de que un hombre con muchas hijas y pocos hijos viva cerca de sus yernos (residencia uxorilocal), y que un hombre con pocas hijas y muchos hijos viva cerca de sus hijos casados (residencia virilocal). Se notará también que en los casos de virilocalidad los antepasados se portan mal con su esposa. Uno abandona a su esposa-zopilote, y otro pega a su mujer-perra. En los casos de residencia uxorilocal el hombre deja a sus parientes políticos (monos, pecarís), y vuelve a su lugar de origen. Es posible que un marido lacandón pegue a su esposa si está enojado con ella, pero no es una regla general. Si la residencia de la pareja es del tipo uxorilocal los padres de la mujer viven muy cerca de ella y podrían acaso protegerla. Empero hemos podido observar en un contexto matrilocal que un hombre pegaba a su esposa sin que sus suegros interviniesen. (Esta actitud sería inconcecible entre los "lacandones meridionales"). Pero si la residencia de la pareja es virilocal los padres de la mujer golpeada no podrían ni siquiera enterarse del pleito. Es posible también que un yerno en servicio tenga ganas de volver a residir con sus padres (como el marido de la mona), pero muchos no lo hacen.

Ya hemos notado que el jaguar es tomador de esposa ante los hombres, y no donador como los otros animales. Otra diferencia es que su modo de residencia marital cambia. Al principio del cuento, después de haber raptado a la hija del antepasado, el jaguar y su esposa viven en la cueva del jaguar, es decir, virilocalmente. Luego de la visita de su suegro y de su propia visita al caserío de sus parientes políticos el jaguar propone a su suegro establecerse cerca de él, y éste acepta. Entonces la residencia marital del jaguar se vuelve uxorilocal. Pero poco después de haberse trasladado al lugar de los hombres, el jaguar perece víctima de una emboscada. Entre los Hach Winik no es poco frecuente que un hombre casado cambie su forma de residencia. Conocemos varios casos de hombres que vivían virilocalmente y, después de tener un conflicto con su padre lo dejaron, y fueron a vivir con sus suegros. El caso inverso también se da. Durante este proceso el jaguar y sus aliados humanos intercambian bienes. Primero el jaguar rapta a la niña; luego vuelve a la casa para robar atole, tortillas, y fuego. Un año después recibe la visita de su suegro y le ofrece carne de caza cruda. Lo ayuda a cargarla, lo acompaña a su casa; allí sus cuñados le regalan atole y tortillas. El jaguar se establece cerca de ellos, les invita a comer en su casa, y les da carne asada. 
Entonces se dan las oposiciones siguientes: virilocalidad: uxorilocalidad: : carne cruda: carne asada.

Entre los Hach Winik las familias de un mismo caserío comparten la carne de caza. Un cazador siempre reserva una porción de la carne para sus suegros, pero no se la da directamente a ellos. En realidad, él da la carne a su esposa quien la limpia, la parte, y luego lleva una porción a su madre. $\mathrm{Si}$ dicha porción es suficiente como para permitir una nueva distribución, la madre compartirá la carne cruda con sus otras hijas o nueras. Vale decir que la representación que nos proporciona el mito es bastante idealizada. De hecho un hombre no invita a sus cuñados a comer carne asada en su casa; la distribución de carne cruda se realiza más bien de un modo discreto e indirecto, a través de las mujeres. En cuanto al atole y a las tortillas que el jaguar recibe de parte de sus aliados eso puede simbolizar la obligación de reciprocidad tan importante en la vida social. Se regala el maíz a cambio de los pecarís que el jaguar dio a su suegro. Pero este intercambio también revela una serie de oposiciones: tomador de esposa: donadores de esposa: carne cruda: maíz procesado.

Otra interpretación atañe al hecho de que el jaguar se ha casado con una niña. Cuando las mujeres son escasas, los Hach Winik contraen matrimonio con niñas. En tal caso el marido espera que su joven esposa llegue a ser nubil para consumar la unión. Sin embargo los esposos comen juntos, y es la madre de la niña quien prepara la comida para su yerno. Aquí también el mito proporciona una imagen idealizada de la realidad. El yerno recibe comida de parte de su suegra, pero la recibe a través de su esposa, y no directamente.

En síntesis, los relatos míticos de los matrimonios entre seres humanos y animales revelan ciertas categorías de la ideología lacandona acerca de la institución matrimonial: la oposición entre donador y tomador de esposa, y la oposición entre residencia virilocal y residencia uxorilocal. Estas categorías inconscientes no sólo se expresan en estos mitos, sino también en otros (Boremanse 1982), así como en la petición ritual de esposa mencionada anteriormente.

Sin embargo no descartamos la idea de que los mitos sean una re-presentación de la realidad etnográfica. Claro, no se trata de un "cuadro siempre fiel" de la realidad, ${ }^{22}$ sino de una re-presentación

22 Dice Lévi-Strauss: "al renunciar a buscar en el mito un cuadro siempre fiel de la realidad etnográfica, ganamos un medio de acceder a veces a las categorías inconscientes" (1972: 60-61). 
simbólica. Pero la oposición entre los dos tipos de residencia marital es un rasgo importante de la organización social de los Hach Winik del norte, y no sólo a nivel ideológico, sino también a nivel empírico, como lo indican nuestros datos estadísticos (Boremanse 1981a:6).

Pero el presente conjunto mítico no sólo refiere, de un modo simbólico, a los aspectos esenciales del matrimonio en la cultura lacandona septentrional, nos dice también algo acerca de la Cultura en general. Los elementos constantes que articulan la estructura común a todos los cuentos simbolizan ciertos rasgos culturales importantes: la Subsistencia, la Alianza (matrimonio y residencia), y la Prestación (intercambio). A nivel empírico estos fenómenos no pueden disociarse; son interdependientes puesto que la subsistencia implica la división del trabajo, la cual se realiza a través de la alianza matrimonial y ésta, a su vez, implica intercambios, prestaciones, así como un patrón de residencia. Sin embargo, la distinción entre Subsistencia (S), Alianza (A), y Prestación (P) nos permite aprehender las unidades constitutivas ${ }^{23}$ del conjunto de mitos, y apreciar sus transformaciones. ${ }^{24}$ En relación con ellas los cinco relatos pueden dividirse en tres grupos: G1 (zopilote/perra), G2 (mono/pecarí), y G3 (jaguar).

En síntesis, la estructura de estas cinco narraciones consideradas en su conjunto, las variaciones de sus elementos básicos, y la expresión de temas persistentes se muestran en el cuadro siguiente.

\begin{tabular}{|c|c|c|}
\hline $\begin{array}{c}G 1 \\
\text { mala cocinera }\end{array}$ & $\begin{array}{c}G 2 \\
\text { mal cazador }\end{array}$ & $\begin{array}{c}G 3 \\
\text { buen cazador }\end{array}$ \\
\hline $\begin{array}{l}\text { esposa raptada } \\
\text { virilocalidad } \\
\text { esposa rechazada }\end{array}$ & $\begin{array}{l}\text { esposo raptado } \\
\text { uxorilocalidad } \\
\text { el marido se escapa }\end{array}$ & $\begin{array}{l}\text { esposa raptada } \\
\text { cambio de viriloca } \\
\text { lidad a uxorilocali } \\
\text { dad } \\
\text { d marido asesinado }\end{array}$ \\
\hline $\begin{array}{l}\text { intercambio de } \\
\text { mujeres }\end{array}$ & servicio de yerno & $\begin{array}{l}\text { intercambio de } \\
\text { alimentos }\end{array}$ \\
\hline
\end{tabular}

23 "les véritables unités constitutives du mythe ne sont pas les relations isolées, mais des paquets de relations, et... c'est seulement sous forme de combinaisons de tels paquets que les unités constitutives acquièrent une fonction signifiante" (Lévi-Strauss 1958: 233-234).

24 Lévi-Strauss "supone que estas narraciones, consideradas en su conjunto total, revelan las transformaciones reiteradas de los elementos de un tema estructural persistente" (Leach 1970: 28). Dicho de otro modo, "las transformaciones... permiten que las similitudes de la estructura se expresen en muchas maneras diferentes" (Yalman 1972: 114). 
Una lectura vertical de este cuadro nos da un resumen de los mitos, mientras que una lectura horizontal nos proporciona información acerca de la cultura tradicional de los Hach Winik del norte. Así la serie SG1G2G3 puede interpretarse del modo siguiente: los medios de subsistencia principales son la caza y la preparación del maíz (cultivado). De la misma manera AG1G2G3 denota la existencia de un sistema de residencia ambivalente, y significa que tanto el rapto como el matrimonio con animales son formas imposibles de alianza. Finalmente PG1G2G3 sintetiza las prestaciones que llevan a cabo los Hach Winik.

Además no se puede negar que los mitos describen "una contradicción insuperable" de la práctica social (Lévi-Straus 1972:60). Lo ideal para el jefe de una familia numerosa sería adquirir yernos sin perder a sus hijos, o sea vivir en el mismo caserío con sus yernos y sus hijos casados. Son muy pocos los hombres que pueden alcanzar esta meta. La mayoría se queda con sus hijos o con sus yernos, pero no con ambos. Las modificaciones relativamente recientes del patrón de asentamiento tradicional de los Hach Winik y la formación de comunidades, cada una con territorio propio, permiten ahora el tipo de residencia ambilocal (un hombre vive a la vez cerca de su padre y cerca de su suegro), lo cual no era posible en el pasado cuando los caseríos se hallaban muy dispersos. Un documento del siglo xviI, que informa acerca de los contactos pacíficos establecidos entre un grupo de Hach Winik y la gente de Palenque dice: "algunos de ellos que se han casado con mujeres de otras rancherías de los mismos montes se quedaron asociados a los suegros, pero se visitan mutuamente" (AGGA A1, 12, 118, 2483).

La historia del jaguar que rapta a una niña y vive con ella virilocalmente, pero luego se establece cerca de sus aliados, les da carne asada después de haberles regalado carne cruda, y finalmente muere asesinado por otro hombre simboliza el hecho de que la contradicción entre los dos principios de organización social es insuperable.

\section{RESÚMENES DE LOS MITOS DE LOS HACH WINIK DEL SUR}

\section{Historia del matrimonio de un hombre con un zopilote}

Un antepasado solicitó una esposa, pero ninguno de sus parientes se la dio. Entonces él habló con sus incensarios, y los dioses le permitieron ver zopilotes. Los encontró bañándose en el agua y lavándose con barro. Eran dos hermanas. El hombre se metió al agua v capturó a una de ellas, mientras la otra se escapó. El ancestro 
llevó la mujer-zopilote a su casa y pidió a su madre que le diera una de sus túnicas. Él estaba feliz por haber conseguido una esposa. Luego llegaron a verla sus vecinos. Ellos la admiraron mucho, porque la encontraban muy bunita. Pero la mujer-zopilote no estaba acostumbrada a comer carne cocida, sólo quería comer carroña. Dejaba podrir la carne, los gusanos eran chiles para ella, y le gustaban mucho. Su marido rogó a los dioses que la hicieran comer como él, y poco a poco ella empezó a comer tortillas, a tomar atole, y finalmente se acostumbró a la comida humana. Luego ella pidió algodón a su suegra y tejió una túnica para su marido. Pero le hizo una túnica de zopilote para poder volar. Después de habérsela puesto, el hombre se parecía a un zopilote. Primero rehusó probar sus alas, pero ella le enseñó a usarlas, y después le gustó. La mujerzopilote ofreció a su suegra cargarla, pero ella no aceptó porque tenía miedo de caer. Entonces se fueron sin ella. La mujer-zopilote invitó a su marido a visitar a su madre, y los dos volaron hacia el cielo. La casa de los zopilotes apestaba porque había mucha carne podrida adentro. La mujer-zopilote dijo a su madre que su casa era sucia y rehusó comer carroña, diciendo que los gusanos le daban disgusto. Después de su visita el antesapado y su esposa-zopilote volvieron a su casa en la tierra.

\section{Historia de Ah Kebatun}

Ah Kebatun, el jaguar, cobró apariencia humana e hizo creer a dos muchachas que él era su padre. En realidad el padre estaba dormido en su casa, pero Ah Kebatun engañó a las niñas, y les dijo que lo acompañaran a la milpa para cosechar frijoles. En el sendero ellas se dieron cuenta de que no estaban siguiendo a su padre, pero era demasiado tarde, el jaguar las raptó. La casa de Kebatun estaba hecha de rocas y no tenía fuego. Cuando las muchachas vieron esto no les gustó. Además extrañaban a su madre Quisieron volver a su casa, pero el jaguar las obligó a quedarse con él y a ser sus esposas. Cuando él se iba a cazar tampoco podían escaparse porque los excrementos de Kebatun eran mágicos. Hablaban con él, y le advertían lo que sus esposas estaban haciendo. Por ejemplo, Ah Kebatun defecaba en la selva y sus excrementos le decían: “iTus esposas se están yendo, Kebatun!" Entonces el jaguar pronto volvía a casa y les decía: " $i \mathrm{Si}$ quieren escaparse las voy a devorar!" De tal modo que nunca pudieron dejarlo. Ah Ke- 
batun comía carne cruda, pero sus esposas lo obligaron a traerles fuego de la casa de sus padres. "No sé lo que es fuego", dijo el jaguar. "Si te quemas lo sabrás", contestaron ellas. Durante la noche Ah Kebatun penetró en la casa de sus suegros, tocó el fuego y se quemó, pero llevó unos palos ardiendo a sus esposas. Luego ellas le pidieron una olla, pero tampoco sabía el jaguar lo que era eso. "La olla está en medio de la choza", le dijeron, "pon tu cabeza adentro y sabrás lo que es". Ah Kebatun regresó a la casa de sus suegros, y puso su cabeza en la olla, pero después ya no pudo sacarla. Empezó a correr en la casa, haciendo tanto ruido que despertó a sus suegros. Por fin se rompió la olla, y el jaguar se escapó, robando otra olla para sus esposas. Luego ellas lo llevaron de visita a su padre, pero él se enfureció con Kebatun y decidió tenderle una emboscada. Un día el hombre y sus hijọs esperaron al jaguar en la selva y lo mataron. También masacraron a sus niños quienes eran pequeños jaguares. Después de eso las dos mujeres volvieron a casa de su padre.

\section{Comparación}

Al comparar estos dos mitos con las versiones correspondientes del noroeste podemos observar las diferencias y las semejanzas siguientes:

Norte

Sur

Zopilote

1) Escasez de mujeres. El ancestro rapta a un zopilote, luego visitan a los padres de ella en el cielo de los zopilotes.

2) La esposa-zopilote sólo come carroña (oposición Naturaleza: Cultura insuperable).

3) El hombre desprecia a su esposa-zopilote.
1) Escasez de mujeres: El ancestro rapta a un zopilote.

2) La esposa-zopilote come carroña, pero luego se acostumbra a la comida humana (Oposición Naturaleza: Gultura neutralizada).

3) Los hombres admiran a la mujer-zopilote. 
4) El ancestro abandona a su esposa y se va a vivir en su milpa.

5) Muere la mujer-zopilote dejando las semillas de calabazas. De ellas nacen sus hijas que el ancestro cede a otro hombre a cambio de una esposa.
4) El ancestro aprende a volar como un zopilote. Su madre rehusa acompañarlos. Vuelan hasta el cielo de los zopilotes.

5) La mujer-zopilote rechaza el modo de vivir de los zopilotes y regresa con su marido a su casa.

Jaguar

1) El jaguar rapta a la niña, y luego vuelve para robar fuego y comida.

2) La esposa del jaguar ruega a su padre que no haga daño a su marido.

3) El jaguar y sus afines se visitan e intercambian regalos de comida.

4) El jaguar cambia de residencia y se establece cerca de sus aliados. Otro hombre mata al jaguar.
1) Ah Kebatun rapta a dos niñas y se casa con ellas (poliginia sororal).

2) Las muchachas quieren escaparse y obligan a Ah Kebatun a arriesgarse para traerles fuego.

3) Ah Kebatun visita a su suegro pero son enemigos.

4) Ah Kebatun es asesinado por su suegro y sus cuñados.

En la versión septentrional del mito del Zopilote son la oposición entre Naturaleza y Cultura y la actitud del antepasado los que acaban con el matrimonio, mientras en la variante meridional esta oposición se ve neutralizada gracias a la actitud de ambos esposos.

La oposición insuperable entre Naturaleza y Cultura connota la imposibilidad de un hombre para contraer matrimonio con un animal, pero también puede simbolizar un rechazo a casarse con gente diferente (Drummond 1977: 857). Los zopilotes sin plumas tienen apariencia humana. El cielo de los zopilotes se parece mucho al mundo humano, los zopilotes viven en sociedad y cultivan maíz como 
los Hach Winik; empero no dejan de formar una 'sociedad distinta'. Desde luego la serie de oposiciones Naturaleza:Cultura :: zopilote: hombre :: Ellos:Nosotros puede referir a una ideología que rechaza la alianza con miembros de otra cultura. Esta interpretación nos parece coherente si se relaciona con el intercambio directo de $\mathrm{mu}$ jeres que ocurre al fin del relato. Las hijas del ancestro y de su esposa-zopilote son completamente humanas y los hombres quieren casarse con ellas. Así, un matrimonio imposible con una mujer extraña se transforma en un doble matrimonio entre gente de la misma sociedad. De este modo la contradicción inicial desaparece, y la negación de la alianza queda neutralizada.

En la versión meridional la oposición Naturaleza:Cultura desempeña otra función. Aquí llega a simbolizar la oposición entre suegros y yerno/nuera. La mujer-zopilote aprende a comer como los humanos, y luego rechaza el modo de vida de sus padres. El ancestro se pone una túnica de plumas y aprende a volar como un zopilote; pero su madre rehusa acompañarlos. O sea, el hombre y su esposa-zopilote se oponen tanto a los padres de ella como a la madre de él. Pero el rechazo de la zopilote hacia sus padres, tanto como el modo de residencia de la pareja (virilocal) reflejan una imagen invertida de la realidad. En la sociedad lacandona del sur, la residencia siempre es uxorilocal y una mujer no rechaza a su madre, al contrario, sigue cooperando con ella después de haberse casado. Como dice Lévi-Strauss, "las instituciones descritas en los mitos pueden ser opuestas a las instituciones reales" (1972: 60). Sin embargo existen casos en que una mujer abandona a sus padres para seguir a un hombre, generalmente un extranjero. En este sentido el mito puede describir una situación real en la cual, debido a la decisión de la mujer, la residencia marital tiene que ser virilocal.

Una última observación acerca del mito del zopilote es que la oposición Naturaleza:Cultura, insuperable en la versión septentrional, se halla más debilitada en la versión meridional como para permitir la unión entre hombre y animal.

Algo similar pasa con el mito del jaguar, pero en sentido contrario. En la versión septentrional la oposición Naturaleza:Cultura se neutraliza porque el jaguar aprende a comer tortillas y carne asada. Además intercambia regalos de comida con su suegro y sus cuñados, y ellos no son responsables de su muerte. En cambio, en la versión meridional son el suegro y los cuñados del jaguar quienes lo 
matan. Allí las oposiciones Naturaleza:Cultura :: Jaguar:Hombres :: Tomador:Donadores de esposas no se resuelven. La relación de amistad y de cooperación entre el jaguar y sus afines (versión del norte) se transforma en una relación de hostilidad (versión del sur). En la variante septentrional es la insuperable oposición entre Naturaleza y Cultura ("los jaguares no deben casarse con humanos") la que impide el matrimonio, mientras en la versión meridional el mero obstáculo radica en la oposición entre tomador y donadores de esposas.

En síntesis, diremos que existen propiedades o elementos invarables comunes a las distintas versiones de estos dos mitos, pero las funciones que cumplen estos elementos varían de una versión a otra, y el mensaje ${ }^{25}$ que proporciona cada variante no es el mismo.

Los mitos de los Hach Winik del sur simbolizan la regla unívoca de residencia uxorilocal de una manera diametralmente opuesta (virilocalidad), pero subrayan el antagonismo entre parientes por afinidad, así como la oposición entre esposos. En una sociedad matrilocal, las mujeres ejercen un control sobre los hombres y los suegros sobre sus yernos; ese es el caso en Lacanha Chan Sayab donde la relación conflictiva entre los sexos así como entre un yerno y sus suegros puede observarse todo el tiempo. Esta situación se halla expresada en los mitos. La mujer-zopilote teje una túnica de zopilote para su marido y le enseña a volar. Las esposas de Kebatun le obligan a traerles fuego y una olla, se burlan de él y lo perjudican. El jaguar amenaza con devorarlas si intentan escapar. Finalmente él perece, víctima de las flechas de su suegro y de sus cuñados.

Las narraciones de los Hach Winik del norte, por otro lado, enfocan más bien la ambivalencia del patrón de residencia, y ponen de relieve el intercambio y las prestaciones. Estos factores desempeñan una función importante en la ideología y la organización de una sociedad donde la relación entre donadores y tomadores de esposas se caracteriza por su ambigüedad. El cuadro siguiente nos ayudará a apreciar mejor la diferencia de ideología entre las dos sociedades de Hach Winik, y cómo se expresa en cada conjunto mítico mediante la oposición entre Naturaleza y Cultura.

25 "Convengamos en llamar armadura a un conjunto de propiedades que se mantienen invariables en dos o más mitos, código al sistema de las funciones asignadas por cada mito a estas propiedades, mensaje al contenido de un mito particular" (Lévi-Strauss 1968:199). 
Norte

Patrón de residencia

ambivalente<smiles>[AlH]</smiles>

Intercambio directo de mujeres dentro de la misma sociedad

\author{
Matrimonio imposible con \\ otra gente \\ $\downarrow$ \\ Naturaleza:Cultura :: \\ Ellos:Nosotros
}

\author{
Sur \\ Residencia matrilocal
$\downarrow$
Oposición entre yerno
y suegros

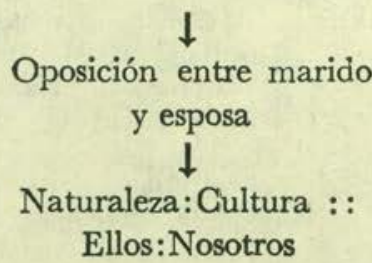

\section{Conclusión}

El análisis estructural de los mitos siempre deja interrogantes debido tanto a la riqueza del material estudiado como a las limitaciones de la técnica de investigación (Douglas 1972: 100). Nos damos cuenta de que nuestro análisis no puede ser exhaustivo, pero nuestro propósito no ha sido el de proporcionar una visión global de la relación entre estos mitos y las culturas lacandonas, sino más bien de enfocar un punto particular: su relación con el matrimonio y los problemas que esta institución implica. Los mitos "representan el pensamiento de la gente sobre sí misma y sobre su condición" (Burridge 1972: 130), y con este ensayo esperamos haber contribuido a una mejor comprensión de la organización social de los Hach Winik a través de las ideas y de los símbolos que les proporciona su mitología.

\section{BIBLIOGRAFIA}

Agca (Archivo General de Centro América)

1790 "Autos hechos en razón de lo mandado de la cédula de 25 de octubre de 1789 , a fin de que se aviolente la reducción de los indios infieles de la región del Lacandón" (A1.12 Exp. 2483 Leg. 118.

1795 "Sobre la buena disposición que manifestaron para abrasar nuestra Santa Fe los indios bárbaros de Sendales a Fr. Mariano Berganzo" (A1.12 Exp. 2486 Leg. 118).

1817 "E1 P. Manuel María de la Chica, sobre que se le auxilie en sus entradas al Lacandón" (A1.12 Exp. 7065 Leg. 334). 
BAer, Ph. Y M.

1949 "Notes on Lacandon marriage", Southwestern Journal of Anthropology, 5:2, 101-106.

Baer, Ph. Y Merrifield, W. R.

1972 Los lacandones de México. Dos estudios. Instituto Nacional Indigenista, México.

BLom, F. y Duby, G.

1955-1957 La selva lacandona, México.

BoAs, F.

1916 Tsimshian Mythology, Informe anual de la Smithsonian Institution, $\mathrm{n}^{2} 31$ (1909-1910), Bureau of American Ethnology, Washington. (Primera reimpresión en 1970, Johnson Reprint Boremanse, D. Corporation).

1974 "An Ethnographic Survey of the Modern Lacandon with a Special Reference to their Neighbours in the Usumacinta and Pasion Drainage during the 16th and 17th Centuries", B. Litt. thesis, Universidad de Oxford. (Una copia de esta tesis está en la Biblioteca Fray Bartolomé de Las Casas, Nabolom, San Cristóbal de Las Casas).

1978 "The social organization of the Lacandon Indians of Mexico", D. Phil. thesis, Universidad de Oxford. (Una copia está en la Biblioteca Fray Bartolomé de Las Casas).

1979 "Magic and Poetry among the Maya Northern Lacandon Therapeutic Incantation", Journal of Latin American Lore, $5: 1$.

1981a "A Comparative St"dy of two Maya Kinship Systems", Sociologus, 31: 1, 1-37.

1981b "Una forma de clasificación simbólica: los encantamientos al balche entre los Lacandones", Journal of Latin American Lore, $7: 2$.

En prensa "A comparative study in Lacandon Maya mythology", Journal

BRUCE, R. D. de la société des Américanistes, 68 (1982).

1975 Lacandon Dream Symbolism, vol. 1, México.

Burridge, K. O. L.

1972 "Lévi-Strauss y el mito" en Estructuralismo y Totemismo, compilador E. R. Leach, Buenos Aires.

De Vos, J.

1980 La Paz de Dios y del Rey. La conquista de la Selva lacandona,

Douglas, M. Chiapas, México.

1972 "El significado del mito", cf. Leach 1972.

DRUMMOND, L.

1977 "Structure and Process in the Interpretation of Southern American Myth: The Arawak Dog Spirit People", American Anthropologist, 79:4, 842-868.

Hellmuth, N.

1972 "Progreso y Notas sobre la investigación etnohistórica de las tierras bajas mayas de los siglos XVI a XIX", América Indigena, 32:1, 179-244.

LANda, Diego DE

Relación de las cosas de Yucatán, Editorial Porrúa, México. 
LEACH, E. R.

1970 Lévi-Strauss, antropólogo y filósofo, Editorial Anagrama, Barcelona.

1972 Estructuralismo, mito y totemismo, compilador E. R. Leach, Buenos Aires.

Lévi-STrauss, Ci.

1958 Anthropologie structurale, Plon, Paris.

1968 Lo crudo y lo cocido, Fondo de Cultura Económica, México.

1972 "La gesta de Asdiwal", cf. Leach 1972.

Reichel-Dolmatoff, G.

1950-1951 Los Kogi, 2 vols. Bogotá.

Roys, R. L.

1965 Ritual of the Bacabs, The University of Oklahoma Press, Norman.

Scholes, F. V. y Roys, R. L. .

1948 The Maya Chontal Indians of Acalan-Tixchel, Carnegie Institution of Washington, Pub. 560, Washington, D.C.

WILBERT

1970 Folk Literature of the Warao Indians, University of California, Los Angeles, 1970.

YALMAN, N.

1972 "Crudo: Cocido: :Naturaleza: Cultura" en, Leach 1972. 